\title{
mRNA overexpression of $B A A L C$ : A novel prognostic factor for pediatric acute lymphoblastic leukemia
}

\author{
ZAHRA AZIZI $^{1}$, SOHEILA RAHGOZAR ${ }^{1}$, ALIREZA MOAFI $^{2}$, \\ MOHAMMAD DABAGHI $^{1}$ and MOTAHAREH NADIMI ${ }^{1}$
}

\begin{abstract}
${ }^{1}$ Division of Cell, Molecular and Developmental Biology, Department of Biology, Faculty of Science, University of Isfahan, Isfahan 81746-73441; ${ }^{2}$ Department of Pediatric Hematology Oncology, Sayed

Al-Shohada Hospital, Isfahan University of Medical Sciences, Isfahan 81856-66153, Iran
\end{abstract}

Received January 28, 2015; Accepted February 20, 2015

DOI: $10.3892 /$ br. 2015.437

\begin{abstract}
BAALC is a novel molecular marker in leukemia that is highly expressed in patients with acute leukemia. Increased expression levels of $B A A L C$ are known as poor prognostic factors in adult acute myeloid and lymphoid leukemia. The purpose of the present study was to evaluate the prognostic significance of the $B A A L C$ gene expression levels in pediatric acute lymphoblastic leukemia (ALL) and its association with $M D R 1$. Using reverse transcription-quantitative polymerase chain reaction (RT-qPCR), the mRNA expression levels of $B A A L C$ and $M R D 1$ were measured in bone marrow samples of 28 new diagnosed childhood ALL patients and 13 children without cancer. Minimal residual disease (MRD) was measured one year after the initiation of the chemotherapy using the RT-qPCR method. The high level expression of $B A A L C$ had a significant association with the pre-B-ALL subtype, leukocytosis and positive MRD after one year of treatment in leukemic patients. In addition, a positive correlation between $B A A L C$ and MDR1 mRNA expression was shown in this group. In conclusion, to the best of our knowledge, the increase of $B A A L C$ expression as a poor prognostic factor for childhood ALL is shown for the first time. Additionally, the correlation between $B A A L C$ and $M D R 1$ in mRNA expression levels can aid for an improved understanding of the mechanism through which $B A A L C$ may function in ALL and multidrug resistance.
\end{abstract}

\section{Introduction}

Acute lymphoblastic leukemia (ALL) is the most common type of cancer in children, responsible for $25-30 \%$ of all cancers in children $<15$ years (1-2). Although the complete remission of

Correspondence to: Dr Soheila Rahgozar, Division of Cell, Molecular and Developmental Biology, Department of Biology, Faculty of Sciences, University of Isfahan, HezarJerib Street, Isfahan 81746-73441, Iran

E-mail: rahgozar@sci.ui.ac.ir

Key words: BAALC gene, acute lymphoblastic leukemia, multidrug resistance, $A B C B 1$ gene this disease is $\sim 70-80 \%$, there remains the risk of relapse in $20-30 \%$ of these children (3-6). Resistance to chemotherapy considerably reduces the rate of treatment success and increases the risk of relapse (7-9).

The $B A A L C$ gene is a marker of hematopoietic precursor cells that was detected for the first time in adult acute myeloid leukemia (AML). The BAALC gene is located on chromosome $8 \mathrm{q} 22.3$ and is expressed in differentiated cells of the nervous system, neuroectoderm-derived tissues (10) and bone marrow hematopoietic precursor cluster of differentiation $34^{+}$cells (11). Studies have shown that increased $B A A L C$ expression causes poor treatment results and resistance to chemotherapy in adult AML and ALL patients (12-14).

Adenosine triphosphate (ATP)-binding cassette sub-family B member (ABCB1), also known as multidrug resistance 1 (MDR1), is an ATP-dependent transporter that is responsible for inhibiting the accumulation of chemotherapy drugs in multidrug resistant cells (15-17). Increased expression levels of $A B C B 1$ in children with ALL leads to a high risk of relapse (18-19). Studies show that the expression levels of the $B A A L C$ gene has a positive association with increased expression levels of $A B C B 1$ in $A M L$ drug resistance. Additionally, the association of high mRNA expression levels of $B A A L C$ with increased levels of $A B C B 1$ contributes to an increased risk of relapse in AML patients, as well as to a decreased rate of complete remission and worse overall survival rate in these patients (12-14). The present study is a novel investigation on $B A A L C$ that examines the mRNA expression levels of this gene in children with ALL and evaluates its association with $A B C B 1$ and the response to therapy in these patients.

\section{Materials and methods}

Patients and sample preparation. Subsequent to obtaining fully informed consent from all the parents, 28 bone marrow samples from children $<15$ years of age (new case), including 5 cases of T-ALL and 23 cases of B-ALL, were studied and compared to 13 bone marrow samples of children with no cancer symptoms. The latter aforementioned samples were those investigated for autoimmune diseases. A total of $2 \mathrm{ml}$ of bone marrow samples was obtained under general anesthesia, added to $0.1 \mathrm{ml}$ heparin and sent to the laboratory on ice. 
Mononuclear cell isolation was performed using Lymphoprep (Axis-Shailed Diagnostics Ltd., Oslo, Norway). Hematological indices were measured with automated analyzers (Technicon H1; Bayer Corp, Etobicoke, ON, Canada).

mRNA isolation and assessment. Total RNA isolation from mononuclear cells was carried out using the RNeasy Mini kit (Qiagen, Hilden, Germany). The amount and quality of extracted RNA was measured by a BioPhotometer (Eppendorf AG, Hamburg, Germany) and the extracted RNA samples were loaded on $1.8 \%$ agarose gel (Merck KGaA, Darmstadt, Germany) for quality assessment. Subsequently, $2 \mu \mathrm{g}$ total RNA was converted to cDNA using a cDNA synthesis kit and random hexamer primers (Fermentas, St. Leon-Rot, Germany). The housekeeping gene, glyceraldehyde 3-phosphate dehydrogenase $(G A P D H)$, was selected as an internal control. Specific forward primers for $B A A L C$, $A B C B 1$ and $G A P D H$ genes were 5'GCCCTCTGACCCAGA AACAG3', 5'GAGGCCGCTGTTCGTTTCCTTTAGGTC3' and 5'GCCCCAGCAAGAGCACAAGAGGAAGA3', respectively. Reverse primers for the abovementioned genes were 5'CTTTTGCAGGCATTCTCTTAGCA3', 5'AGATTCATT CGACCTCGCGCTCCT3' and 5'CATGGCAACTGTGAG GAGGGGAGAT3', respectively. SYBER Premix Ex Taq II Real Time kit (Takara Bio, Inc., Tokyo, Japan) was used for reverse transcription-quantitative polymerase chain reaction (RT-qPCR) that was carried out through an optimized program (3-5 min pre-incubation at $95^{\circ} \mathrm{C}, 10-15 \mathrm{sec}$ denaturation at $95^{\circ} \mathrm{C}, 30 \mathrm{sec}$ annealing at $59-61^{\circ} \mathrm{C}$ and $30 \mathrm{sec}$ product expansion at $72^{\circ} \mathrm{C}$ in $35-45$ cycles). Correlations were investigated between the $B A A L C$ and $A B C B 1$ mRNA expression levels. Any association between the $B A A L C$ gene expression levels and certain prognostic factors of childhood ALL, including age, white blood cell (WBC) counts, platelet counts and hemoglobin levels, were also examined at the onset of the disease.

Evaluation of treatment response. Newly diagnosed patients were treated based on the Australian and New Zealand Children's Cancer Study Group ALL study 8 protocol (http://www.anzctr.org.au/trial_view.aspx?ID=1568). To assess treatment response in the year following the initiation of the treatment, the amount of minimal residual disease (MRD) was studied using RT-qPCR to detect monoclonal immunoglobulin heavy chain gene rearrangement. Persistence of monoclonality, referred to as $\mathrm{MRD}^{+}$, was considered as a poor response to therapy and drug resistance.

Statistical analysis. Statistical analysis was performed using the Graphpad Prism 5 software. Correlations between gene expression levels and ALL prognostic factors were measured using Pearson and Spearman's correlation tests. Association between gene expression and response to therapy was performed using Fisher's exact test. Data are shown as mean \pm standard error of the mean (SEM) and $\mathrm{P}<0.05$ was considered to indicate a statistically significant difference.

\section{Results}

Patients. A total of 28 patients were involved in the study. One of the patients succumbed during the induction stages due to

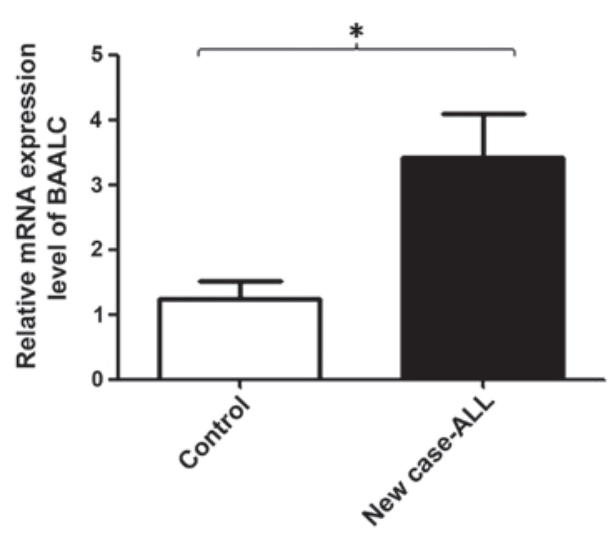

Figure 1. Relative mRNA expression levels of $B A A L C$ in bone marrow samples of children with acute lymphoblastic leukemia (ALL) and children with no sypmtoms of cancer. ${ }^{*} \mathrm{P} \leq 0.05$.

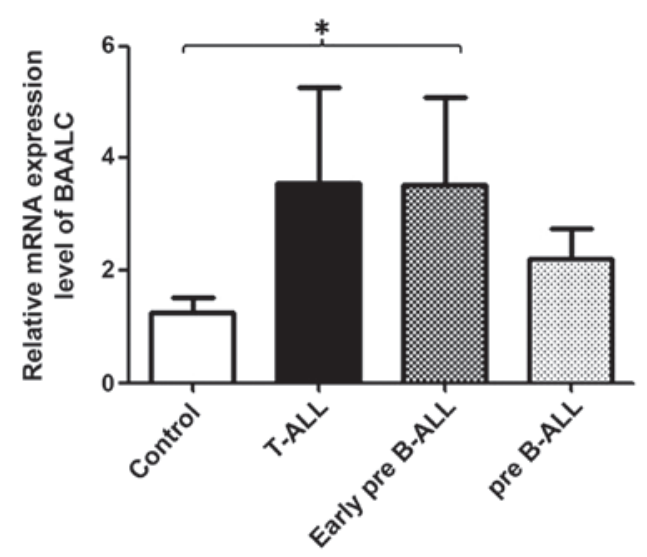

Figure 2. Relative mRNA expression levels of $B A A L C$ in different subtypes of acute lymphoblastic leukemia (ALL). ${ }^{*} \mathrm{P} \leq 0.05$.

infection. Two patients, who relapsed during the first year of treatment, were considered as treatment resistant patients. The remaining 25 patients were investigated for signs of MRD at the end of the first year of chemotherapy. Monoclonality remained persistent for 6 patients who were considered $\mathrm{MRD}^{+}$ and resistant to therapy.

mRNA expression levels of the BAALC gene. The mRNA expression levels of $B A A L C$ were significantly different between de novo patients and the control group (mean $\pm \mathrm{SEM}$, $3.67 \pm 0.66$ vs. $1.24 \pm 0.27$, respectively; $\mathrm{P}=0.04$ ) (Fig. 1).

The comparison of the BAALC gene expression level between the ALL subgroups (T-ALL, early pre-B cell and pre B-cell) showed a significant difference only for early pre-B cell subtype compared to the control group (mean \pm SEM, $3.52 \pm 1.56$ vs. $1.24 \pm 0.27$, respectively; $\mathrm{P}=0.03$ ) (Fig. 2).

Association between the BAALC gene expression and response to therapy. The association between the BAALC gene mRNA expression levels and response to therapy was assessed in 27 ALL patients. BAALC expression levels in $\mathrm{MRD}^{+}$patients were significantly higher compared to the MRD patients and the control group (mean \pm SEM, $4.59 \pm 1.28$ vs. $1.92 \pm 0.48$ and $1.24 \pm 0.27$, respectively; $P \leq 0.0001$ ) (Fig. 3). The results of the 
Table I. Association between the BAALC expression levels and response to therapy.

\begin{tabular}{lcccc}
\hline & \multicolumn{3}{l}{ Therapy response, $\mathrm{n}$} & \\
\cline { 2 - 3 } $\begin{array}{l}\text { Cut-off point for } \\
\text { BAALC expression }\end{array}$ & $\mathrm{MRD}^{+}$ & MRD- $^{-}$ & P-value & Odds ratio \\
\hline >2-fold & 7 & 4 & 0.001 & 4.14 \\
$<2$-fold & 4 & 10 & & \\
\hline
\end{tabular}

MRD, minimal residual disease.

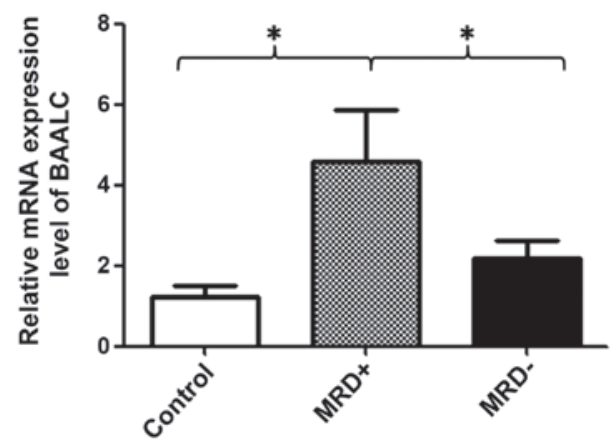

Figure 3. Association between the mRNA expression levels of $B A A L C$ and response to therapy. The BAALC expression levels in $\mathrm{MRD}^{+}$patients are significantly higher than those in MRD' patients and also the control group. MRD, minimal residual disease. ${ }^{*} \mathrm{P} \leq 0.05$.

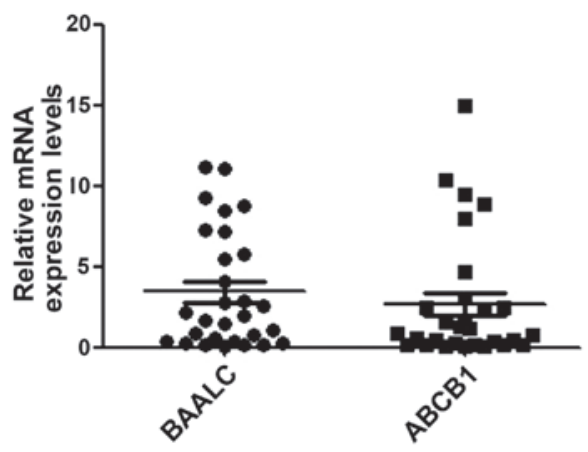

Figure 4. Dot plot demonstration showing a correlation between the expression levels of the $B A A L C$ and $A B C B 1$ genes.

Fisher's exact test showed that when BAALC mRNA expression levels are $>2$-fold more than that of the control group, the risk of drug resistance $\left(\mathrm{MRD}^{+}\right)$will be 4.14 -fold higher $(\mathrm{P}=0.001)$ (Table I).

Correlation between $B A A L C$ and $A B C B 1$. Results of the Pearson and Spearman's correlation tests showed a significant association between $B A A L C$ and $A B C B 1$ expression at mRNA levels $(\mathrm{P}=0.03)$. Based on the Pearson and Spearman's correlation tests, it was observed that a simultaneous increase in mRNA expression levels of $B A A L C$ and $A B C B 1$ increases the risk of relapse by 4.55 -fold (Fig. 4).

BAALC gene expression and certain prognostic factors. Possible correlations between the $B A A L C$ gene overexpression and several prognostic factors in childhood ALL, including age, WBC counts, platelet counts and hemoglobin levels, were investigated. Spearman's correlation tests demonstrated a significantly positive correlation between the mRNA expression levels of $B A A L C$ and WBC count in childhood ALL $(\mathrm{P}=0.04)$. There was no significant correlation between the increased expression levels of $B A A L C$ and age $(\mathrm{P}=0.41)$, gender $(\mathrm{P}=0.40)$, platelet count $(\mathrm{P}=0.31)$ and hemoglobin levels $(\mathrm{P}=0.18)$.

\section{Discussion}

To the best of our knowledge, the present study identifies the role of $B A A L C$ as a prognostic biomarker in childhood ALL for the first time. In addition, the data showed that $B A A L C$ gene expression in de novo patients is 2.4 times more than in the control group. However, we do not believe that $B A A L C$ may be considered as a valuable diagnostic factor for ALL, as $B A A L C$ gene overexpression is reported only in immature cells that were increased primarily at the onset of the disease prior to sampling $(11,20-21)$. What makes this phenotype more clinically important is the uneven overexpression of the gene in different leukemic blast cells. The present results indicate a significant increase in mRNA expression levels of $B A A L C$ in $\mathrm{MRD}^{+}$patients compared to the control group, which indicates that the immature cells expressing more of the $B A A L C$ gene are the more resistant cells to chemotherapy. These data suggest that $B A A L C$ has an adverse impact on response to therapy. Therefore, increased expression of $B A A L C$ is introduced as a poor prognostic factor for childhood ALL. The first studies to validate the poor prognostic value of $B A A L C$ were performed in adult leukemic patients or children with AML (14,22-24). These studies indicate an association between the increased mRNA expression levels of $B A A L C$ with poor treatment response and early drug resistance. Consequently, $B A A L C$ is proposed as a risk factor for adult leukemia patients (13-14,21). These findings are consistent with the present study, demonstrating that the 2-fold increase of $B A A L C$ expression in $\mathrm{MRD}^{+}$patients compared to normal levels may elevate the risk of relapse by 4.14 times. These findings allow for the development of improved therapies. By contrast, the present study may open up more opportunities to understand the multifactorial pathophysiology of ALL.

The pathophysiological role of BAALC is under investigation. However, the precise function of this protein in cancer biology has remained undefined. High expression levels of $B A A L C$ are reported to increase proliferation and decrease apoptosis in leukemic cell lines (25). By contrast, it is suggested that BAALC may have an impact on multidrug resistance through association with the ABC transporters in AML. The present study has examined, for the first time, the association between $B A A L C$ and $A B C B 1$, one member of this large family, in childhood ALL. The mRNA expression profile of $A B C B 1$ in childhood ALL was recently studied by our group and was suggested to be a risk factor for treatment failure and multidrug resistance in this disease (18-19). Our findings show that the increase of $B A A L C$ expression is positively associated with $A B C B 1 \mathrm{mRNA}$ expression profiles. However, it is unclear whether these two genes are expressed dependently, or that they are two separate prognostic factors that function in 
different pathways. The mechanism by which these two genes operate awaits further confirmation.

Cytogenetic studies were not available in the present study, however, statistical tests were performed to investigate the association between $B A A L C$ mRNA expression levels and several clinical characteristics, including gender, WBC and platelet counts, hemoglobin levels and serum biochemistries such as lactate dehydrogenase. Results showed that among the aforementioned ALL risk factors, high BAALC expression mRNA levels were solely associated with the increased numbers of WBCs $>50 \times 10^{3} / \mu 1$ at the time of diagnosis. This association is supported by the potential role of $B A A L C$ in leukemic cells proliferation and resistance to apoptosis, which was previously mentioned in this section.

In conclusion, $B A A L C \mathrm{mRNA}$ overexpression is proposed as a negative prognostic factor in childhood ALL, which increases the risk of resistance to chemotherapy. It is suggested elsewhere that BAALC may promote leukemic cell proliferation and inhibit their apoptosis. The present results show that simultaneous overexpression of $B A A L C$ and $A B C B 1$ in $\mathrm{MRD}^{+}$children with ALL may introduce a second mechanism through which $B A A L C$ may apply its adverse effect on response to treatment. The exact function of $B A A L C$ in childhood ALL and the manner of its communication with $\mathrm{ABC}$ transporters for increasing the risk of resistance to therapy remain to be established.

\section{References}

1. Linet MS, Ries LA, Smith MA, Tarone RE and Devesa SS: Cancer surveillance series: Recent trends in childhood cancer incidence and mortality in the United States. J Natl Cancer Inst 91: 1051-1058, 1999.

2. Pui C-H: Acute lymphoblastic leukemia in children. Curr Opin Oncol 12: 3-12, 2000.

3. le Viseur C, Hotfilder M, Bomken S, Wilson K, Röttgers S, Schrauder A, Rosemann A, Irving J, Stam RW, Shultz LD, et al: In childhood acute lymphoblastic leukemia, blasts at different stages of immunophenotypic maturation have stem cell properties. Cancer Cell 14: 47-58, 2008.

4. Belson M, Kingsley B and Holmes A: Risk factors for acute leukemia in children: A review. Environ Health Perspect 115: 138-145, 2007.

5. Kelly PN, Dakic A, Adams JM, Nutt SL and Strasser A: Tumor growth need not be driven by rare cancer stem cells. Science 317: 337, 2007.

6. Kennedy JA, Barabé F, Poeppl AG, Wang JC and Dick JE: Comment on 'Tumor growth need not be driven by rare cancer stem cells'. Science 318: 1722, 2007.

7. Pui C-H, Relling MV and Downing JR: Acute lymphoblastic leukemia. N Engl J Med 350: 1535-1548, 2004.

8. Ross DD: Novel mechanisms of drug resistance in leukemia. Leukemia 14: 467-473, 2000

9. Swerts K, De Moerloose B, Dhooge C, Laureys G, Benoit Y and Philippé J: Prognostic significance of multidrug resistance-related proteins in childhood acute lymphoblastic leukaemia. Eur J Cancer 42: 295-309, 2006.

10. Tanner SM, Austin JL, Leone G, Rush LJ, Plass C, Heinonen K, Mrózek K, Sill H, Knuutila S, Kolitz JE, et al: BAALC, the human member of a novel mammalian neuroectoderm gene lineage, is implicated in hematopoiesis and acute leukemia. Proc Natl Acad Sci USA 98: 13901-13906, 2001.
11. Baldus CD, Tanner SM, Kusewitt DF, Liyanarachchi S, Choi C, Caligiuri MA, Bloomfield CD and de la Chapelle A: BAALC, a novel marker of human hematopoietic progenitor cells. Exp Hematol 31: 1051-1056, 2003.

12. Guo X, Shi P, Chen F, Zha J, Liu B, Li R, Dong H, Zheng H and Xu B: Low MDR1 and BAALC expression identifies a new subgroup of intermediate cytogenetic risk acute myeloid leukemia with a favorable outcome. Blood Cells Mol Dis 53: 144-148, 2014.

13. Langer C, Radmacher MD, Ruppert AS, Whitman SP, Paschka P, Mrózek K, Baldus CD, Vukosavljevic T, Liu CG, Ross ME, et al; Cancer and Leukemia Group B (CALGB): High BAALC expression associates with other molecular prognostic markers, poor outcome and a distinct gene-expression signature in cytogenetically normal patients younger than 60 years with acute myeloid leukemia: A Cancer and Leukemia Group B (CALGB) study. Blood 111: 5371-5379, 2008

14. Kühnl A, Gökbuget N, Stroux A, Burmeister T, Neumann M, Heesch S, Haferlach T, Hoelzer D, Hofmann WK, Thiel E, et al: High BAALC expression predicts chemoresistance in adult B-precursor acute lymphoblastic leukemia. Blood 115: 3737-3744, 2010

15. Leonard GD, Fojo T and Bates SE: The role of ABC transporters in clinical practice. Oncologist 8: 411-424, 2003.

16. Gillet J-P and Gottesman MM: Mechanisms of multidrug resistance in cancer. Methods Mol Biol 596: 47-76, 2010.

17. Marques DS, Sandrini JZ, Boyle RT, Marins LF and Trindade GS: Relationships between multidrug resistance (MDR) and stem cell markers in human chronic myeloid leukemia cell lines. Leuk Res 34: 757-762, 2010.

18. Rahgozar S, Moafi A, Abedi M, Entezar-E-Ghaem M, Moshtaghian J, Ghaedi K, Esmaeili A and Montazeri F: mRNA expression profile of multidrug-resistant genes in acute lymphoblastic leukemia of children, a prognostic value for $\mathrm{ABCA} 3$ and ABCA2. Cancer Biol Ther 15: 35-41, 2014.

19. Abedi M, Rahgozar S, Moafi A, et al: Evaluation of the expression profile of MDR1 gene and assessment of its prognostic value in childhood ALL. Sci J Iran Blood Transfus Organ 10: 326-334 2014.

20. Baldus CD, Tanner SM, Ruppert AS, Whitman SP, Archer KJ, Marcucci G, Caligiuri MA, Carroll AJ, Vardiman JW, Powell BL, et al: BAALC expression predicts clinical outcome of de novo acute myeloid leukemia patients with normal cytogenetics: A Cancer and Leukemia Group B Study. Blood 102: 1613-1618, 2003.

21. Baldus CD, Martus P, Burmeister T, Schwartz S, Gökbuget N, Bloomfield CD, Hoelzer D, Thiel E and Hofmann WK: Low ERG and BAALC expression identifies a new subgroup of adult acute T-lymphoblastic leukemia with a highly favorable outcome. J Clin Oncol 25: 3739-3745, 2007.

22. Gregory TK, Wald D, Chen Y, Vermaat JM, Xiong Y and Tse W: Molecular prognostic markers for adult acute myeloid leukemia with normal cytogenetics. J Hematol Oncol 2: 23, 2009.

23. Weber S, Alpermann T, Dicker F, Jeromin S, Nadarajah N, Eder C, Fasan A, Kohlmann A, Meggendorfer M, Haferlach C, et al: BAALC expression: A suitable marker for prognostic risk stratification and detection of residual disease in cytogenetically normal acute myeloid leukemia. Blood Cancer J 4: e173, 2014.

24. Mizushima Y, Taki T, Shimada A, Yui Y, Hiraumi Y, Matsubara H, Watanabe M, Watanabe K, Kamitsuji Y, Hayashi Y, et al: Prognostic significance of the BAALC isoform pattern and CEBPA mutations in pediatric acute myeloid leukemia with normal karyotype: A study by the Japanese Childhood AML Cooperative Study Group. Int J Hematol 91: 831-837, 2010.

25. Xu B, Chen G, Shi P, Guo X, Xiao P, Wang W and Zhou S: shRNA-Mediated BAALC knockdown affects proliferation and apoptosis in human acute myeloid leukemia cells. Hematology 17: 35-40, 2012. 